\section{(6) OPEN ACCESS}

\title{
Oral contraceptives, breastfeeding and the risk of developing rheumatoid arthritis: results from the Swedish EIRA study
}

\author{
Cecilia Orellana, ${ }^{1}$ Saedis Saevarsdottirr, ${ }^{1,2}$ Lars Klareskog, ${ }_{1}^{2}$ Elizabeth W Karlson, ${ }^{3}$ \\ Lars Alfredsson, ${ }^{1,4}$ Camilla Bengtsson $^{1}$
}

\begin{abstract}
- Additional material is published online only. To view please visit the journal online (http://dx.doi.org/10.1136/ annrheumdis-2017-211620).
\end{abstract}

${ }^{1}$ Institute of Environmental Medicine, Karolinska Institutet, Stockholm, Sweden

${ }^{2}$ Rheumatology Unit, Department of Medicine, Solna, Karolinska University Hospital and Karolinska Institutet,

Stockholm, Sweden

${ }^{3}$ Brigham and Women's Hospital Harvard Medical School, Boston, Massachusetts, USA

${ }^{4}$ Centre for Occupational and Environmental Medicine, Stockholm County Council, Stockholm, Sweden

Correspondence to Cecilia Orellana, Institute of Environmental Medicine, Karolinska Institutet, Box 210, S1171 77 Stockholm, Sweden; cecilia.orellana@ki.se

Received 10 April 2017 Revised 15 June 2017 Accepted 24 June 2017 Published Online First 28 July 2017

\section{(1) crossanat}

To cite: Orellana $C$, Saevarsdottir S, Klareskog L, et al. Ann Rheum Dis 2017;76:1845-1852.

\section{ABSTRACT}

Objectives To study whether oral contraceptive (OC) use or breastfeeding (BF) influence the risk of rheumatoid arthritis (RA), stratifying the cases by presence/absence of anticitrullinated protein antibodies (ACPA), and whether these factors interact with known risk factors in the development of ACPA-positive RA. Methods Women aged $\geq 18$ years, participants in the population-based case-control Swedish Epidemiological Investigation of RA study (2641 cases/4251 controls) completed an extensive questionnaire regarding $\mathrm{OC}$, $\mathrm{BF}$ and potential confounders. We calculated ORs, with 95\% Cls, adjusted for age, residential area, smoking and alcohol consumption. Attributable proportion due to interaction (AP) was estimated to evaluate presence of interaction.

Results Compared with never users, ever and past OC users had a decreased risk of ACPA-positive RA (OR=0.84 (95\% Cl 0.74 to 0.96$) ; O R=0.83(95 \% \mathrm{Cl}$ 0.73 to 0.95$)$, respectively). No significant associations were found for ACPA-negative RA. Long duration of $O C$ use ( $>7$ years vs never use) decreased the risk of both ACPA-positive $(p=0.0037)$ and ACPA-negative $R A(p=0.0356)$. A history of long BF decreased the risk only of ACPA-positive RA in a dose-dependent manner $(p=0.0086)$, but this trend did not remain after adjustments. A significant interaction was observed between the lack of $O C$ use and smoking ( $A P=0.28$ (95\% CI 0.14-0.42)) on the risk of ACPA-positive RA. No interactions were found for BF.

Conclusions $O C$ decreased the risk of RA, especially ACPA-positive RA, where an interaction with smoking was observed. A long duration of $O C$ use decreased the risk of both disease subsets. We could not confirm an association between $\mathrm{BF}$ and a decreased risk of either ACPA-positive or ACPA-negative RA.

\section{INTRODUCTION}

Rheumatoid arthritis (RA) is among the most common autoimmune diseases, with a complex interplay of genetic and environmental factors involved in its aetiology. ${ }^{12}$ Since the disease is two to three times more common among women as compared with men, ${ }^{3-5}$ it has been suggested that hormonal and reproductive factors might partly explain this sex difference.

Regarding oral contraceptive (OC) use and the risk of RA, some studies have shown an inverse association, ${ }^{6-11}$ but the majority of reports have been unable to demonstrate an association. ${ }^{12-23}$ Only a few previous reports have taken seropositivity into account, either exploring the classic rheumatoid factor (RF) 69111521 or presence/absence of anticitrullinated protein antibodies (ACPA). ${ }^{12} 14$ Furthermore, disparate results so far might be explained by methodological issues, such as the use of prevalent cases for analysis, ${ }^{14}$ inclusion of non-population controls $^{911}$ or relatively few cases. ${ }^{11} 1221$

Breastfeeding (BF) has been associated with a decreased risk of RA, ${ }^{13} 152425$ and a long duration of BF seems to have the strongest association. ${ }^{1524}$ However, some studies have found an increased RA risk. ${ }^{126}$ Analyses taking seropositivity into account have yielded disparate results. ${ }^{12} 131526$ Among these, Berglin et al reported that a longer BF history provided a higher risk of RA among those carrying the PTPN22 1858T variant or were positive for ACPA or RF. ${ }^{12}$ Apart from these studies, the influence of BF on ACPA-positive/ACPA-negative RA has not been further investigated.

For the ACPA-positive subgroup of RA, several risk factors have been identified, including smoking, the PTPN22*R620W $(1858 \mathrm{C} / \mathrm{T})$ risk allele and the HLA-DRB1 shared epitope (SE) allele. ${ }^{127-31}$ In contrast, for the ACPA-negative subgroup of RA, only a few risk factors have been identified. ${ }^{2} 31$ ACPA-status and the classic RF highly correlate, and risk factors for seropositive/negative RA behave similarly. ${ }^{2} 3032$

The aim of this study was to investigate the association between both $\mathrm{OC}$ use and total history of $\mathrm{BF}$ among parous women, and the risk of developing RA stratifying the cases by ACPA-status (positive/ negative), using data from a large population-based case-control study. Moreover, the aim was to explore potential additive interactions between $\mathrm{BF}$ and OC, respectively, in regard to known risk factors for ACPA-positive disease, namely smoking status, presence of SE alleles and PTPN22 gene.

\section{METHOD}

\section{Study design}

This study was based on data from the Swedish Epidemiological Investigation of RA (EIRA) comprising women above 18 years, living in defined geographical areas of Sweden, between 1996 and 2014. The general design of the EIRA study has been described in detail elsewhere. ${ }^{33}$ Incident cases of RA were diagnosed by rheumatologists and included if they fulfilled either the American College of Rheumatology 1987 criteria $^{34}$ or the 
latest 2010 RA criteria. ${ }^{35}$ Twenty-four cases were diagnosed according to the new criteria alone. Controls were randomly selected from the national population register and matched to the cases by age (5-year group) and residential area. For further details, see online supplementary text (online supplementary file 1). All participants provided written informed consent, and ethical approval was obtained from the Regional Ethical Review Board at Karolinska Institutet, Stockholm, Sweden.

\section{Data collection}

Participants completed an extensive questionnaire regarding lifestyle and environmental exposures, including $\mathrm{OC}$ use, BF and potential confounders. Information about OC use was available for the entire study period, whereas information on BF history among parous women was only available from 2006.

Between 1996 and 2014, a total of 2809 cases and 5312 controls were identified; of these, 2676 cases (95\%) and 4251 controls (80\%) answered the questionnaire. Blood samples were available from all participating cases.

\section{Antibody assays and genotyping}

Blood samples were assayed for ACPA-status using the Immunoscan-RA Mark2 ELISA test (Euro-Diagnostica, Malmö, Sweden). ${ }^{3637}$ The cut-off value for ACPA-positive RA was $25 \mathrm{U} /$ $\mathrm{mL}$. A total of 35 and 13 cases lacking information on ACPAstatus were excluded from the $\mathrm{OC}$ and $\mathrm{BF}$ analyses, respectively.

Genotyping of the PTPN22 and HLA-DRB1 genes was conducted as previously described. ${ }^{38} 39$ Among HLA-DRB1 genes, $D R B 1 * 01, D R B 1 * 04$ and $D R B 1 * 10$ genes were defined as SE alleles. Any genotype containing 1 or 2 of these genes was considered as having 'any SE allele', versus those not having any of the genes ('no SE alleles').

\section{Exposures}

The year in which the first symptoms of RA occurred was defined as the index-year for each case. Controls were then assigned the same index-year as their matched case.

Current users of OCs were defined as those who were currently using OCs during the index-year and who had started at least the year before index-year. Participants who started OC use during index-year (four cases/seven controls) and those with missing information on OC use (59 cases/115 controls) were excluded from the analyses. Past users were defined as those who used OCs in the past and had stopped at least the year before the index-year. Ever users were defined as current and past users while never users were women who had not used OCs at any time before the index-year.

Parous women were defined as those who had given birth before or during the index-year. Total BF history among parous women was calculated as the sum of the duration of BF for each child born and categorised as $0-6,7-12$ and $\geq 13$ months, according to quartile distribution among controls. Participants with missing information on BF history (78 cases/148 controls) were excluded from analyses. Parous women who did not breast feed (two cases/14 controls) were included in the reference category.

\section{Statistical analysis}

Odds ratios (OR) with 95\% confidence intervals (CI) of RA overall, ACPA-positive and ACPA-negative RA, associated with $\mathrm{OC}$ use and BF were calculated by means of unconditional logistic regression. Regarding OC use, current/past/ever users were compared with never users. Duration of OC use was categorised according to the median value among controls $(\leq 7 />7$ years). For the BF analyses, the shortest duration of BF (0-6 months) was used as the reference category.

All analyses were adjusted for the matching variables (age and residential area). We conducted additional adjustments (each variable was investigated separately) for parity (yes/no), number of children $(1,2,3$ and $\geq 4)$, body mass index $(<25 / \geq 25 \mathrm{~kg} /$ $\mathrm{m}^{2}$ ), menopausal status, use of postmenopausal hormone therapy (ever/never), age at menarche ( $\leq 11,12,13$ and $\geq 14$ years), age at first birth (<22, 22-24, 25-29 and $>29$ years), time between last delivered child and the index-year (0-24, 25-30, 31-37 and >37 years), index-year intervals, university education (yes/no), pack-years of cigarette smoking $(0-<10$, $\geq 10-<20$ and $\geq 20$ ) and alcohol consumption (low (including non-drinkers), medium and high). We also adjusted for OC use when analysing BF as the main exposure and vice versa. Only smoking and alcohol consumption made a change in the ORs and were retained in the final analyses.

Potential interaction was estimated using departure from additivity of effects (additive interaction), as suggested by Rothman. ${ }^{40}$ We tested for interactions in the same manner for both OC use and BF with well-established risk factors of RA: smoking, SE alleles and PTPN22 risk allele.

To evaluate interaction, the attributable proportion due to interaction (AP) was calculated together with the $95 \% \mathrm{CI}^{41}$ The $\mathrm{AP}$ is the proportion of the incidence among people exposed to two interacting factors, indicating their joint effect apart from the sum of their independent effects. For further details, see online supplementary text.

All analyses were carried out using the Statistical Analysis System (SAS) V.9.4.

\section{RESULTS}

In total, 2641 cases and 4251 controls were available for the OC analyses. Overall, 1756 (66.5\%) cases were ACPA-positive and the mean time between symptom onset and diagnosis was 10 months for both ACPA subsets. A total of 2578 cases and 4129 controls were included in the OC analyses after all exclusions. For BF, a total of 1242 cases and 2658 controls were available for analysis (for the period 2006-2014), of which 884 cases and 1949 controls where parous women with available BF history. Baseline characteristics of participants are presented in table 1.

\section{$O C$ use and risk of RA}

Ever users of OCs had a decreased odds of developing RA overall compared with never users $(\mathrm{OR}=0.87,95 \% \mathrm{CI} 0.78$ to 0.97). The OR for current and past users were 0.85 (95\% CI 0.68 to 1.06$)$ and 0.87 (95\% CI 0.78 to 0.98$)$, respectively. The association between ever and past $\mathrm{OC}$ use was significant for ACPA-positive, but not for the smaller subset of ACPA-negative $\mathrm{RA}$, and remained significant after adjustment for pack-years of smoking and alcohol consumption (table 2).

A longer duration of ever OC use (above the median value of 7 years) was associated with a decreased risk of RA overall $(\mathrm{OR}=0.81,95 \% \mathrm{CI} 0.71$ to 0.92$)$. The trend with a longer duration was significant for both ACPA-positive $(p=0.0037)$ and ACPA-negative RA ( $p=0.0356)$. Similar result was observed for past OC use except for ACPA-negative RA, probably due to lack of power (table 3). Separate analyses for OC using RF yielded similar results (data not shown). 
Table 1 Characteristics of cases and controls. EIRA, Sweden, 1996-2014

\begin{tabular}{|c|c|c|c|}
\hline & \multicolumn{2}{|l|}{$\begin{array}{l}\text { Cases }(n=2641) \\
N(\%), \text { mean } \pm S D\end{array}$} & \multirow[t]{2}{*}{$\begin{array}{l}\text { Controls }(n=4251) \\
N(\%), \text { mean } \pm \text { SD }\end{array}$} \\
\hline & $\begin{array}{l}\text { ACPA-positive RA } \\
1756(66.5 \%)\end{array}$ & $\begin{array}{l}\text { ACPA-negative RA } \\
885(33.5 \%)\end{array}$ & \\
\hline Age at inclusion (years) & $50.9 \pm 13.0$ & $52.0 \pm 13.5$ & $51.4 \pm 13.4$ \\
\hline Age at menarche (years) & $13.2 \pm 1.4$ & $13.2 \pm 1.4$ & $13.1 \pm 1.5$ \\
\hline Parous & $1375(78.3)$ & $718(81.1)$ & $3376(79.4)$ \\
\hline Number of children & $2.2 \pm 1.2$ & $2.2 \pm 0.8$ & $2.2 \pm 0.9$ \\
\hline Age at first birth (years) & $24.8 \pm 4.9$ & $24.5 \pm 4.9$ & $25.6 \pm 5.0^{*}$ \\
\hline Age at menopause (years) & $49.6 \pm 5.6$ & $49.8 \pm 5.3$ & $50.0 \pm 5.4$ \\
\hline \multicolumn{4}{|l|}{ Oral contraceptive uset } \\
\hline Ever & $1135(64.7)$ & $582(65.8)$ & $2862(67.4) \ddagger$ \\
\hline Current & $134(7.6)$ & $61(6.9)$ & $331(7.8)$ \\
\hline Past & $1001(57.1)$ & $521(58.9)$ & 2531 (59.6)‡ \\
\hline Never & $572(32.6)$ & $289(32.7)$ & $1267(29.9)$ \\
\hline Missing & $46(2.6)$ & $13(1.5)$ & $115(2.7)$ \\
\hline \multicolumn{4}{|l|}{ Breast feeding (months)§ } \\
\hline None & $1(0.1)$ & $1(0.3)$ & $14(0.7)$ \\
\hline $1-6$ & $193(28.7)$ & $80(27.6)$ & $519(24.7)$ \\
\hline $7-12$ & $192(28.6)$ & $83(28.6)$ & $574(27.4)$ \\
\hline$\geq 13$ & $234(34.8)$ & $100(34.5)$ & $842(40.1)$ \\
\hline Missing & $52(7.7)$ & $26(9.0)$ & $148(7.1)$ \\
\hline \multicolumn{4}{|c|}{ Total duration of breast feeding (months) according to parity§ } \\
\hline One child & $6.4 \pm 5.6$ & $4.8 \pm 2.7$ & $6.9 \pm 5.4$ \\
\hline Two children & $11.7 \pm 8.2$ & $11.7 \pm 8.1$ & $12.4 \pm 8.3$ \\
\hline Three children or more & $22.5 \pm 18.1$ & $19.5 \pm 12.9$ & $20.7 \pm 13.9$ \\
\hline Ever use of PMHף & $117(26.3)$ & $67(29.7)$ & $412(29.5)$ \\
\hline $\mathrm{BMI} \geq 25 \mathrm{~kg} / \mathrm{m}^{2}$ & $749(42.7)$ & $409(46.2)$ & $1704(40.1) \ddagger$ \\
\hline University degree & $469(26.7)$ & $251(28.4)$ & $1425(33.5)^{*}$ \\
\hline Ever smoker & $1175(66.9)$ & $531(60.0)$ & $2266(53.3)^{*}$ \\
\hline \multicolumn{4}{|l|}{ Pack-years } \\
\hline Never smokers & $571(32.5)$ & $348(39.3)$ & $1943(45.7)$ \\
\hline $0-10$ & $367(20.9)$ & $185(21.0)$ & $963(22.7) \ddagger$ \\
\hline $10-20$ & $316(18.0)$ & $132(14.9)$ & $531(12.5)^{*}$ \\
\hline$\geq 20$ & $409(23.3)$ & $149(16.8)$ & $530(12.5)^{*}$ \\
\hline Other & $82(4.7)$ & $63(7.1)$ & $243(5.7) \ddagger$ \\
\hline Missing & $11(0.6)$ & $8(0.9)$ & $41(0.9)$ \\
\hline \multicolumn{4}{|l|}{ Alcohol consumption } \\
\hline Non-drinkers & $213(12.1)$ & $100(11.3)$ & $330(7.8)^{*}$ \\
\hline Low & $892(50.9)$ & $418(47.3)$ & $1991(46.9)$ \\
\hline Moderate & $408(23.3)$ & $228(25.8)$ & $1045(24.6)$ \\
\hline High & $235(13.4)$ & $138(15.6)$ & $864(20.4)^{*}$ \\
\hline Missing & $5(0.3)$ & $0(0)$ & $14(0.3)$ \\
\hline
\end{tabular}

Baseline characteristics among participants who replied to the questionnaire, excluding cases lacking ACPA-status (35 cases).

Information on age at menarche and age at menopause available for 1211 cases/2596 controls and 757 cases/1548 controls, respectively.

A pack-year is defined as 20 cigarettes smoked every day for 1 year. The category 'Other' includes those smoking other tobacco than cigarettes (eg, cigarillos, cigars or pipe tobacco).

Alcohol consumption defined as number of drinks per week (one drink=12 $\mathrm{g}$ of alcohol) and categorised according to the quartile distribution among the controls. The two lowest categories (non-drinkers and low consumption) were merged for analyses.

${ }^{*} p$ Value $<0.0001$ for the difference between cases and controls.

tOral contraceptive use after exclusion of four cases/seven controls who initiated use during the index-year. Ever oral contraceptive use is the sum of current and past use. $\neq p$ Value $<0.05$ for the difference between cases and controls.

§Information on breastfeeding available for 884 cases and 1949 controls (all parous women) from 2006. Quartile distribution among controls, with the two highest categories merged into one.

ПOnly among postmenopausal women.

ACPA, anticitrullinated protein antibodies; BMI, body mass index; EIRA, Epidemiological Investigation of Rheumatoid Arthritis; PMH, postmenopausal hormone therapy; RA, rheumatoid arthritis.

\section{$B F$ and risk of RA}

Compared with women who breast fed for 0-6 months, those who breast fed their children for 7-12 months had an OR of
0.93 (95\% CI 0.75 to 1.14$)$ of developing RA overall, whereas BF for 13 months or more had an OR of 0.77 (95\% CI 0.63 to 0.94$)$. This declining trend was statistically significant for 


\begin{tabular}{|c|c|c|c|c|}
\hline ACPA status & Oral contraceptive use ${ }^{*}$ & $\mathrm{Ca} / \mathrm{Co}$ & OR $(95 \% \mathrm{Cl}) \dagger$ & OR $(95 \% \mathrm{Cl}) \neq$ \\
\hline \multirow[t]{5}{*}{ RA overall } & Ever & $1717 / 2862$ & 0.87 (0.78 to 0.97$)$ & 0.87 (0.78 to 0.98$)$ \\
\hline & Current & $195 / 331$ & 0.85 (0.68 to 1.06$)$ & 0.89 (0.71 to 1.12$)$ \\
\hline & Past & $1522 / 2531$ & 0.87 (0.78 to 0.98$)$ & 0.87 (0.78 to 0.98$)$ \\
\hline & Never & $861 / 1267$ & 1.0 & 1.0 \\
\hline & Missing & $59 / 115$ & - & - \\
\hline \multirow[t]{5}{*}{ ACPA-positive } & Ever & $1135 / 2862$ & 0.84 (0.74 to 0.95$)$ & 0.84 (0.74 to 0.96$)$ \\
\hline & Current & $134 / 331$ & $0.86(0.67$ to 1.11$)$ & $0.92(0.71$ to 1.19$)$ \\
\hline & Past & $1001 / 2531$ & 0.84 (0.74 to 0.95$)$ & 0.83 (0.73 to 0.95$)$ \\
\hline & Never & $572 / 1267$ & 1.0 & 1.0 \\
\hline & Missing & $46 / 115$ & - & - \\
\hline \multirow[t]{5}{*}{ ACPA-negative } & Ever & $582 / 2862$ & 0.94 (0.80 to 1.10$)$ & 0.93 (0.79 to 1.10$)$ \\
\hline & Current & $61 / 331$ & 0.83 (0.59 to 1.17$)$ & 0.81 (0.57 to 1.16$)$ \\
\hline & Past & $521 / 2531$ & 0.95 (0.80 to 1.12$)$ & $0.94(0.79$ to 1.11$)$ \\
\hline & Never & $289 / 1267$ & 1.0 & 1.0 \\
\hline & Missing & $13 / 115$ & - & - \\
\hline
\end{tabular}

\footnotetext{
*Participants who started OC use during index-year (four cases/seven controls) were excluded from the analysis. Ever is the sum of current and past OC users. †Adjusted for age and residential area.

¥Adjusted for age, residential area, smoking (pack-years) and alcohol consumption (low (including non-drinkers), medium and high).

ACPA, anticitrullinated protein antibodies; $\mathrm{Ca} / \mathrm{Co}$, number of cases/controls; EIRA, Epidemiological Investigation of Rheumatoid Arthritis; OC, oral contraceptive; RA, rheumatoid arthritis.
}

ACPA-positive, but not for ACPA-negative RA. These estimates were attenuated after adjustment for smoking and alcohol consumption (table 4). Analyses using RF instead of ACPA gave similar results (data not shown).

\section{Interaction analyses}

Never OC use among never smokers was not associated with risk of ACPA-positive RA (OR=0.99, 95\% CI 0.81 to 1.21$)$. Compared with never smoking women which had used OCs, women who had smoked and used OCs had an OR=1.71 (95\% CI 1.47 to 1.99), whereas women who had smoked and never used OCs had an OR=2.34 (95\% CI 1.95 to 2.82) (table 5). Moreover, a significant interaction on the additive scale was found between smoking and never use of $\mathrm{OCs}(\mathrm{AP}=0.28$, $95 \% \mathrm{CI} 0.14$ to 0.42 ) regarding the risk of ACPA-positive RA, indicating that among smokers the risk was more pronounced in never OC users than in ever OC users. No significant interactions were found between OC use and SE alleles, the PTPN22 gene or between $\mathrm{BF}$ and any of the three factors explored (data not shown).

\section{DISCUSSION}

In this large population-based case-control study of incident RA, with careful matching between cases and controls and extensive exposure information, we found that women who had ever used OCs had a significantly decreased risk of developing RA. The estimates were similar for current and past use, although only significant in the larger group of past users. When stratifying by ACPA-status, the association was only significant for ACPA-positive RA in both crude and adjusted models. A significant

Table 3 ORs of developing RA overall and ACPA-positive/ACPA-negative RA according to duration of oral contraceptive use. EIRA, Sweden, 1996-2014

\begin{tabular}{|c|c|c|c|c|c|c|c|}
\hline \multirow[b]{2}{*}{ ACPA-status } & \multirow{2}{*}{$\begin{array}{l}\text { Duration of } O C \\
\text { use }{ }^{*}\end{array}$} & \multicolumn{2}{|c|}{ Ever OC use } & \multicolumn{2}{|c|}{ Current $\mathrm{OC}$ use } & \multicolumn{2}{|c|}{ Past $O C$ use } \\
\hline & & $\mathrm{Ca} / \mathrm{Co}$ & OR $(95 \% \mathrm{Cl}) \dagger$ & $\mathrm{Ca} / \mathrm{Co}$ & OR $(95 \% \mathrm{Cl}) \dagger$ & $\mathrm{Ca} / \mathrm{Co}$ & OR $(95 \% \mathrm{Cl})+$ \\
\hline \multirow[t]{3}{*}{ RA overall } & Never & $852 / 1245$ & 1.0 & $852 / 1245$ & 1.0 & $852 / 1245$ & 1.0 \\
\hline & $>7$ years & $835 / 1481$ & 0.81 (0.71 to 0.92 ) & $134 / 242$ & 0.99 (0.74 to 1.33$)$ & $701 / 1239$ & 0.81 (0.71 to 0.93$)$ \\
\hline & $p$-trend & & 0.0014 & & 0.9982 & & 0.0021 \\
\hline \multirow[t]{2}{*}{ ACPA-positive } & Never & $565 / 1245$ & 1.0 & $565 / 1245$ & 1.0 & $565 / 1245$ & 1.0 \\
\hline & $p$-trend & & 0.0037 & & 0.8011 & & 0.0039 \\
\hline \multirow[t]{4}{*}{ ACPA-negative } & Never & $287 / 1245$ & 1.0 & $287 / 1245$ & 1.0 & $287 / 1245$ & 1.0 \\
\hline & $\leq 7$ years & $309 / 1348$ & 1.04 (0.86 to 1.25 ) & $20 / 85$ & 1.15 (0.61 to 2.18 ) & $289 / 1263$ & 1.04 (0.86 to 1.25$)$ \\
\hline & $>7$ years & $265 / 1481$ & $0.82(0.67$ to 0.99$)$ & $39 / 242$ & 1.09 (0.68 to 1.74$)$ & $226 / 1239$ & 0.83 (0.67 to 1.01$)$ \\
\hline & $p$-trend & & 0.0356 & & 0.7056 & & 0.0636 \\
\hline
\end{tabular}

26 cases and 55 controls lacked information on duration of oral contraceptive use.

*Duration of $O C$ use categorised according to median value among controls.

†Adjusted for age, residential area, smoking (pack-years) and alcohol consumption (low (including non-drinkers), medium and high).

ACPA, anticitrullinated protein antibodies; $\mathrm{Ca} / \mathrm{Co}$, number of cases/controls; ElRA, Epidemiological Investigation of Rheumatoid Arthritis; OC, oral contraceptives; RA, rheumatoid arthritis. 


\begin{tabular}{|c|c|c|c|c|}
\hline ACPA-status & Breastfeeding* & $\mathrm{Ca} / \mathrm{Co}$ & OR $(95 \% \mathrm{Cl}) \dagger$ & OR $(95 \% \mathrm{Cl}) \neq$ \\
\hline \multirow[t]{5}{*}{ RA overall } & $\leq 6$ months & $275 / 533$ & 1.0 & 1.0 \\
\hline & $7-12$ months & $275 / 574$ & 0.93 (0.75 to 1.14 ) & 0.99 (0.80 to 1.23$)$ \\
\hline & $\geq 13$ months & $334 / 842$ & 0.77 (0.63 to 0.94$)$ & 0.88 (0.71 to 1.08$)$ \\
\hline & Missing & $78 / 148$ & - & - \\
\hline & $p$-value trend & - & 0.0075 & 0.1919 \\
\hline \multirow[t]{5}{*}{ ACPA-positive } & $\leq 6$ months & $194 / 533$ & 1.0 & 1.0 \\
\hline & $7-12$ months & $192 / 574$ & 0.91 (0.72 to 1.15 ) & 0.99 (0.78 to 1.26$)$ \\
\hline & $\geq 13$ months & $234 / 842$ & 0.74 (0.59 to 0.93 ) & 0.86 (0.68 to 1.09 ) \\
\hline & Missing & $52 / 148$ & - & - \\
\hline & $p$-value trend & - & 0.0086 & 0.2096 \\
\hline \multirow[t]{5}{*}{ ACPA-negative } & $\leq 6$ months & $81 / 533$ & 1.0 & 1.0 \\
\hline & $7-12$ months & $83 / 574$ & 0.97 (0.70 to 1.35 ) & 1.01 (0.72 to 1.42$)$ \\
\hline & $\geq 13$ months & $100 / 842$ & 0.83 (0.60 to 1.15 ) & 0.91 (0.65 to 1.27$)$ \\
\hline & Missing & $26 / 148$ & - & - \\
\hline & $p$-value trend & - & 0.2405 & 0.5446 \\
\hline
\end{tabular}

*Breastfeeding duration categorised according to quartiles values among controls, merging the two highest categories.

†Adjusted for age and residential area.

¥Adjusted for age, residential area, smoking (pack-years) and alcohol consumption (low (including non-drinkers), medium and high).

ACPA, anticitrullinated protein antibodies; $\mathrm{Ca} / \mathrm{C}$, number of cases/controls; EIRA, Epidemiological Investigation of Rheumatoid Arthritis; RA, rheumatoid arthritis.

dose-response association was observed for duration of ever OC use both for ACPA-positive and ACPA-negative RA. Non-use of OC significantly interacted with smoking regarding the risk of ACPA-positive RA. Furthermore, BF also decreased the risk of RA in a dose-dependent manner (total duration), but this trend was only significant for ACPA-positive RA and did not maintain after adjustments.

EIRA has the advantage of being one of the largest population-based case-control studies comprising incident cases of
RA with concordant information on environmental and genetic factors. The selection of controls (randomly and continuously from the same study base as the cases) minimises the possible selection bias in this step. Another major strength of our study was the possibility to adjust our results with respect to several potential confounders.

Several limitations of our study should be mentioned. First, although the participation proportion among controls was high $(80 \%)$, selection bias may have occurred if the controls did not

Table 5 ORs of developing ACPA-positive RA for subjects exposed to OC and ever smoking/HLA-DRB1 SE alleles/PTPN22 in women aged 18 years or above. EIRA, Sweden, 1996-2014

\begin{tabular}{|c|c|c|c|c|}
\hline OC use* & Smoking & $\mathrm{Ca} / \mathrm{Co}$ & OR $(95 \% \mathrm{Cl}) \dagger$ & OR $(95 \% \mathrm{Cl}) \ddagger$ \\
\hline Ever & Never & $358 / 1205$ & 1.0 & 1.0 \\
\hline Never & Never & $201 / 684$ & 1.05 (0.86 to 1.28$)$ & $0.99(0.81$ to 1.21$)$ \\
\hline Never & Ever & $364 / 563$ & 2.33 (1.94 to 2.80 ) & 2.34 (1.95 to 2.82 ) \\
\hline AP§ & - & - & 0.29 (0.15 to 0.43$)$ & 0.28 (0.14 to 0.42$)$ \\
\hline OC use* & SE alleles & $\mathrm{Ca} / \mathrm{Co}$ & OR $(95 \% \mathrm{Cl}) \dagger$ & OR $(95 \% \mathrm{Cl}) \ddagger$ \\
\hline Never & None & $60 / 215$ & 1.24 (0.86 to 1.77$)$ & 1.26 (0.87 to 1.83$)$ \\
\hline Ever & Any & $657 / 531$ & 4.99 (3.93 to 6.33$)$ & 5.11 (4.00 to 6.54$)$ \\
\hline Never & Any & $348 / 243$ & 6.62 (5.03 to 8.70 ) & 6.28 (4.73 to 8.34$)$ \\
\hline AP§ & & & 0.21 (0.04 to 0.38$)$ & $0.14(-0.05$ to 0.34$)$ \\
\hline OC use* & PTPN22 alleles & $\mathrm{Ca} / \mathrm{Co}$ & OR $(95 \% \mathrm{Cl}) \dagger$ & OR $(95 \% \mathrm{Cl}) \ddagger$ \\
\hline AP§ & & & $0.0007(-0.32$ to 0.33$)$ & $-0.02(-0.37$ to 0.33$)$ \\
\hline
\end{tabular}

* Since ever OC use was associated with a decreased risk of ACPA-positive RA, the risk category included non-OC users for each interaction analysis, which was separately conducted for smoking, SE alleles and PTPN22.

†Adjusted for matching variables (age and residential area) and alcohol consumption.

¥Adjusted for matching variables (age and residential area), pack-years of smoking and alcohol consumption (low (including non-drinkers), medium and high).

$\S$ The AP estimates the proportion of the excess risk that is due to the interaction per se (factor $A+$ factor $B$ ) according to the formula $R R_{A B}-R R_{A}-R_{B}+1 / R_{R A B}($ where $\mathrm{RR}=$ relative risk).

ACPA, anticitrullinated protein antibodies; AP, attributable proportion due to interaction; Ca/Co, number of cases/controls; EIRA, Epidemiological Investigation of Rheumatoid Arthritis; OC, oral contraceptives; RA, rheumatoid arthritis; SE, shared epitope. 
reflect the exposure frequency in the study base. However, both $\mathrm{BF}$ and ever OC use among controls were very similar to the high frequency of $\mathrm{BF}^{42}$ and reported $\mathrm{OC}$ use ${ }^{43}$ among Swedish women, respectively. Second, we did not have detailed information regarding OC preparations or doses, being only able to conduct analyses on OC use as a whole.

Regarding OC use, our finding of a decreased risk of developing RA is in accordance with previous reports. ${ }^{6-11}$ Although most previous studies have not observed a statistically significant association, ${ }^{12-21}$ some results have suggested a protective effect, but the sample size might have been inadequate to reach definite conclusions. Only borderline associations have been observed in a few recent meta-analyses. ${ }^{22}{ }^{23}$ Our results are in agreement with those from Doran et $a l,{ }^{6}$ who reported a decreased risk among ever $(\mathrm{OR}=0.57$ (95\% CI 0.35 to 0.91$)$ but not among current $(\mathrm{OR}=1.0$ (95\% CI 0.4 to 2.52) OC users. Another case-control study performed in Sweden showed a non-significant association for ever $(\mathrm{OR}=0.70,95 \% \mathrm{CI} 0.40$ to 1.24$)$ and current $(\mathrm{OR}=1.21,95 \% \mathrm{CI} 0.58$ to 2.52$) \mathrm{OC}$ users, but the association for past users was significant $(\mathrm{OR}=0.37,95 \% \mathrm{CI} 0.16$ to 0.86$){ }^{8}$ These findings are in line with our results, although they used old criteria (year 1958) for RA diagnosis. In line with our findings, Berglin et al found a protective effect with OC use $>7$ years. $^{12}$

Previous reports taking seropositivity into account have yielded contradictory results. ${ }^{6911} 12141521$ Doran et al found a protective effect of OC exposure on the risk of RF-positive $(\mathrm{OR}=0.36,95 \% \mathrm{CI} 0.18$ to 0.72$)$ but not RF-negative RA $(\mathrm{OR}=0.982$, 95\% CI 0.46 to 2.10$){ }^{6}$ By contrast, Pedersen et al reported an increased risk of ACPA-positive RA among ever users of $\mathrm{OC}(\mathrm{OR}=1.65,95 \% \mathrm{CI} 1.06$ to 2.57$) .{ }^{14}$ However, the inclusion of prevalent cases (diagnosed within 5 years) might entail bias. Our result was notably mainly restricted to ACPA-positive RA and estimates only slightly modified after adjustments. Similar results using RF instead of ACPA-status corroborate the high correlation between ACPA-status and the classic RF.

The current knowledge on the association between BF and RA has not reached firm conclusions. In a large cohort study, Karlson et al found a decreased risk of RA among women who breast fed for more than 12 months, with a significant trend with increased duration of $\mathrm{BF}^{15}$ Restricting the analyses to RF positive patients, a similar reduction was found for a total BF duration of $\geq 24$ months. In line with these results, a study conducted in Sweden showed a decreased risk of RA among women who breast fed their children for more than a year, with similar trends for RF-negative/RF-positive RA. ${ }^{13}$ A similar result was obtained by a recent cross-sectional study in an Asian population. ${ }^{24}$ Our estimates were attenuated after adjustments for smoking and alcohol consumption, which indicates their role as important confounders in this study. Analyses using RF yielded similar results as those for ACPA-status. However, in a nested casecontrol study, Berglin et al found a strong association between $\mathrm{BF}$ and later development of $\mathrm{RA}(\mathrm{OR}=4.8$, 95\% CI 1.43 to $15.8)$ with a higher risk with increasing time of $\mathrm{BF}$ and greater among ACPA-positive cases. ${ }^{12}$ Similar findings were reported by Brennan and Silman, with a higher risk for RF-positive RA among women who breast fed. ${ }^{26}$ These opposite results might be explained by methodological issues (small number of cases (70) and recruitment via a media campaign, respectively). Finally, a recently published systematic review and meta-analysis reported a decreased risk of RA, whether with a longer or shorter duration of $\mathrm{BF}^{25}$ Our study confirms and extends these findings by adding the stratification according to ACPA-status, which to our knowledge has not been explored using a large dataset as in our present study.

To the best of our knowledge, no previous study has found evidence of interaction between $\mathrm{OC}$ and/or BF and smoking habits or major genetic risk factors of RA, respectively. The significant interaction between lack of OC use and smoking indicates that the risk of ACPA-positive RA associated with smoking is higher among women who never used OCs than among those who did. However, since both smoking and the use of OC have been linked to an increased predisposition to venous thrombotic events (VTE), women with a history of VTEs (especially if they smoke) might be recommended not to use OC by their physician. We can therefore not exclude the possibility that our findings on an interaction between non-OC use and smoking merely reflects that smoking women, who have an increased RA risk, do not receive OC prescription as often. The physiopathology of RA is complex and not fully understood, but our findings may contribute to the knowledge regarding mechanisms of importance for the development of RA.

The postpartum period soon after delivery has been described as a time of higher risk for the onset of RA. ${ }^{19}$ The immunostimulating effect of the hormone prolactin, levels of which are elevated during BF, might explain this increased risk immediately after childbirth. ${ }^{44}$ However, recent findings indicate that prolactin might act more as a regulator of inflammation, with protective and regenerative functions. ${ }^{45}$ Since elevated prolactin levels do not support our findings, a potential biological mechanism might be a prolonged anti-inflammatory effect of progesterone. It has been shown that elevated progesterone levels during pregnancy remain high during BF through expression of progesterone receptors in lymphocytes. ${ }^{46}$ Finally, another potential mechanism might be an anti-inflammatory effect of cortisol, which has been found to be significantly higher among postmenopausal women with a history of $\mathrm{BF}^{47}$

The potential effect of hormones contained in OC preparations might vary according to dose and type. Although such information was not available in the present study, the protective effect seems to differ between ACPA-subsets and with a longer duration of OC use, supporting the hypothesis of a doseresponse effect.

The protective effect of OC use on the risk of ACPA-positive RA is in line with our previous finding of a reduced risk of ACPA-positive RA, among women who used postmenopausal hormone therapy. ${ }^{48}$ On the other hand, the finding of a protective effect of $\mathrm{BF}$ on the risk of ACPA-positive (in the crude model), but not ACPA-negative RA, is in line with our previous finding of a risk of ACPA-negative but not ACPA-positive RA during the postpartum period. ${ }^{49}$ All of these findings together support the notion of RA as two different disease entities with different risk factors patterns.

In summary, we found an inverse relationship between $\mathrm{OC}$ use and the subsequent development of RA, especially ACPA-positive RA. An interaction between never OC use and smoking was also observed for this subgroup of disease, implying that among smokers, the risk was more pronounced in never OC users than in ever OC users. A trend was observed for longer duration of $\mathrm{BF}$ and decreased risk of ACPA-positive RA, although not significant after adjustments. In this large population-based study, we were able to address these questions more thoroughly than has been possible before, by examining disease subsets separately, in the context of other risk factors and by considering many potential confounders. Further research is required to explore the biological mechanisms behind our findings and whether hormonal factors have different impact on the ACPA-subsets of RA. 
Acknowledgements We would like to thank Marie-Louise Serra and Lena Nise for excellent assistance with the collection of data. We would also like to thank all cases and controls who participated in the study as well as the clinicians and nurses in the EIRA study group.

Contributors CO conducted the statistical analyses and drafted the manuscript; $C B$ initiated the study and was responsible for the analysis, interpreting the results and revising the manuscript; $L A, L K$ and $C B$ contributed to study design; and $L A, L K$, EWK and SS contributed to data interpretation and critical revision of the manuscript for important intellectual content. All authors have read and approved the final manuscript.

Funding This study was supported by grants from the Swedish Medical Research Council, the Swedish Research Council for Health, Working Life and Welfare, King Gustav Vâ€ ${ }^{T M}$ S 801 -year foundation, Vinnova, the Swedish Foundation for Strategic Research, the Swedish Rheumatic Foundation, the Stockholm County Council, the Insurance Company AFA, the Innovative Medicines Initiative 1 supported BTCure project and the National Institutes of Health ( $\mathrm{NIH}, \mathrm{ARO47782)}$. The funding sources had no role in the reporting of the study or in the decision to submit the manuscript for publication.

Competing interests No, there are no competing interests.

Patient consent Obtained.

Ethics approval This study was approved by the Regional Ethical Review Board at Karolinska Institutet, Stockholm, Sweden.

Provenance and peer review Not commissioned; externally peer reviewed.

Open Access This is an Open Access article distributed in accordance with the Creative Commons Attribution Non Commercial (CC BY-NC 4.0) license, which permits others to distribute, remix, adapt, build upon this work non-commercially, and license their derivative works on different terms, provided the original work is properly cited and the use is non-commercial. See: http://creativecommons.org/ licenses/by-nc/4.0/

(c) Article author(s) (or their employer(s) unless otherwise stated in the text of the article) 2017. All rights reserved. No commercial use is permitted unless otherwise expressly granted.

\section{REFERENCES}

1 Karlson EW, Deane K. Environmental and gene-environment interactions and risk of rheumatoid arthritis. Rheum Dis Clin North Am 2012:38:405-26.

2 Klareskog L, Catrina Al, Paget S. Rheumatoid arthritis. Lancet 2009;373:659-72.

3 Humphreys $\mathrm{JH}$, Verstappen $\mathrm{SM}$, Hyrich $\mathrm{KL}$, et al. The incidence of rheumatoid arthritis in the UK: comparisons using the 2010 ACR/EULAR classification criteria and the 1987 ACR classification criteria. results from the Norfolk Arthritis Register. Ann Rheum Dis 2013;72:1315-20.

4 Kvien TK, Uhlig T, Ødegård S, et al. Epidemiological aspects of rheumatoid arthritis: the sex ratio. Ann N Y Acad Sci 2006;1069:212-22.

5 Doran MF, Pond GR, Crowson CS, et al. Trends in incidence and mortality in rheumatoid arthritis in Rochester, Minnesota, over a forty-year period. Arthritis Rheum 2002;46:625-31.

6 Doran MF, Crowson CS, O'Fallon WM, et al. The effect of oral contraceptives and estrogen replacement therapy on the risk of rheumatoid arthritis: a population based study. J Rheumatol 2004;31:207-13.

7 Reckner Olsson A, Skogh T, Wingren G. Comorbidity and lifestyle, reproductive factors, and environmental exposures associated with rheumatoid arthritis. Ann Rheum Dis 2001;60:934-9

8 Allebeck P, Ahlbom A, Ljungström K, et al. Do oral contraceptives reduce the incidence of rheumatoid arthritis? A pilot study using the Stockholm County medical information system. Scand J Rheumatol 1984;13:140-6.

9 Vandenbroucke JP, Valkenburg HA, Boersma JW, et al. Oral contraceptives and rheumatoid arthritis: further evidence for a preventive effect. Lancet 1982;2:839-42.

10 Koepsell T, Dugowson C, Voigt L, et al. Preliminary findings from a case-control study of the risk of rheumatoid arthritis in relation to oral contraceptive use. $\mathrm{Br} J$ Rheumatol 1989;28 Suppl 1:41-5. discussion.

11 Hazes JM, Dijkmans BC, Vandenbroucke JP, et al. Reduction of the risk of rheumatoid arthritis among women who take oral contraceptives. Arthritis Rheum 1990;33:173-9.

12 Berglin E, Kokkonen $\mathrm{H}$, Einarsdottir E, et al. Influence of female hormonal factors, in relation to autoantibodies and genetic markers, on the development of rheumatoid arthritis in northern Sweden: a case-control study. Scand J Rheumatol 2010;39:454-60.

13 Pikwer M, Bergström U, Nilsson JA, et al. Breast feeding, but not use of oral contraceptives, is associated with a reduced risk of rheumatoid arthritis. Ann Rheum Dis 2009:68:526-30.

14 Pedersen $\mathrm{M}$, Jacobsen $\mathrm{S}$, Klarlund $\mathrm{M}$, et al. Environmental risk factors differ between rheumatoid arthritis with and without auto-antibodies against cyclic citrullinated peptides. Arthritis Res Ther 2006;8:R133.
15 Karlson EW, Mandl LA, Hankinson SE, et al. Do breast-feeding and other reproductive factors influence future risk of rheumatoid arthritis? results from the nurses' Health Study. Arthritis Rheum 2004;50:3458-67.

16 Merlino LA, Cerhan JR, Criswell LA, et al. Estrogen and other female reproductive risk factors are not strongly associated with the development of rheumatoid arthritis in elderly women. Semin Arthritis Rheum 2003;33:72-82.

17 Pope JE, Bellamy N, Stevens A. The lack of associations between rheumatoid arthritis and both nulliparity and infertility. Semin Arthritis Rheum 1999;28:342-50.

18 Brennan P, Bankhead C, Silman A, et al. Oral contraceptives and rheumatoid arthritis: results from a primary care-based incident case-control study. Semin Arthritis Rheum 1997;26:817-23.

19 Silman A, Kay A, Brennan P. Timing of pregnancy in relation to the onset of rheumatoid arthritis. Arthritis Rheum 1992:35:152-5.

20 Spector TD, Roman E, Silman AJ. The pill, parity, and rheumatoid arthritis. Arthritis Rheum 1990:33:782-9.

21 del Junco DJ, Annegers JF, Luthra HS, et al. Do oral contraceptives prevent rheumatoid arthritis? JAMA 1985;254:1938-41.

22 Qi S, Xin R, Guo W, et al. Meta-analysis of oral contraceptives and rheumatoid arthritis risk in women. Ther Clin Risk Manag 2014;10:915-23.

23 Chen Q, Jin Z, Xiang C, et al. Absence of protective effect of oral contraceptive use on the development of rheumatoid arthritis: a meta-analysis of observational studies. Int J Rheum Dis 2014;17:725-37.

24 Adab P, Jiang CQ, Rankin E, et al. Breastfeeding practice, oral contraceptive use and risk of rheumatoid arthritis among chinese women: the Guangzhou Biobank Cohort Study. Rheumatology 2014;53:860-6.

25 Chen H, Wang J, Zhou W, et al. Breastfeeding and risk of Rheumatoid Arthritis: a Systematic Review and Metaanalysis. J Rheumatol 2015;42:1563-9.

26 Brennan P, Silman A. Breast-feeding and the onset of rheumatoid arthritis. Arthritis Rheum 1994;37:808-13.

27 Källberg H, Ding B, Padyukov L, et al. Smoking is a Major preventable risk factor for rheumatoid arthritis: estimations of risks after various exposures to cigarette smoke. Ann Rheum Dis 2011;70:508-11.

28 Padyukov L, Seielstad M, Ong RT, et al. A genome-wide association study suggests contrasting associations in ACPA-positive versus ACPA-negative rheumatoid arthritis. Ann Rheum Dis 2011:70:259-65.

29 Raychaudhuri S. Recent advances in the genetics of rheumatoid arthritis. Curr Opin Rheumatol 2010;22:109-18.

30 Klareskog L, Stolt P, Lundberg K, et al. A new model for an etiology of rheumatoid arthritis: smoking may trigger HLA-DR (shared epitope)-restricted immune reactions to autoantigens modified by citrullination. Arthritis Rheum 2006;54:38-46.

31 Lahiri M, Morgan C, Symmons DP, et al. Modifiable risk factors for RA: prevention, better than cure? Rheumatology 2012;51:499-512.

32 Terao C, Ohmura K, Ikari K, et al. Effects of smoking and shared epitope on the production of anti-citrullinated peptide antibody in a japanese adult population. Arthritis Care Res 2014;66:1818-27.

33 Bengtsson C, Berglund A, Serra ML, et al. Non-participation in EIRA: a populationbased case-control study of rheumatoid arthritis. Scand J Rheumatol 2010;39:344-6.

34 Arnett FC, Edworthy SM, Bloch DA, et al. The American Rheumatism Association 1987 revised criteria for the classification of Rheumatoid arthritis. Arthritis Rheum 1988:31:315-24.

35 Aletaha D, Neogi T, Silman AJ, et al. 2010 Rheumatoid arthritis classification criteria: an American College of Rheumatology/European League Against Rheumatism collaborative initiative. Arthritis Rheum 2010;62:2569-81.

36 Rantapää-Dahlqvist S. Diagnostic and prognostic significance of autoantibodies in early rheumatoid arthritis. Scand J Rheumatol 2005;34:83-96.

37 Rönnelid J, Wick MC, Lampa J, et al. Longitudinal analysis of citrullinated protein/ peptide antibodies (anti-CP) during 5 year follow up in early rheumatoid arthritis: anti-cp status predicts worse disease activity and greater radiological progression. Ann Rheum Dis 2005:64:1744-9.

38 Padyukov L, Silva C, Stolt P, et al. A gene-environment interaction between smoking and shared epitope genes in HLA-DR provides a high risk of seropositive rheumatoid arthritis. Arthritis Rheum 2004;50:3085-92.

39 Olerup 0, Zetterquist H. HLA-DR typing by PCR amplification with sequence-specific primers (PCR-SSP) in 2 hours: an alternative to serological DR typing in clinical practice including donor-recipient matching in cadaveric transplantation. Tissue Antigens 1992;39:225-35.

40 Rothman KJ, ed. Epidemiology: an introduction. 2nd ed. USA: Oxford University Press, 2012.

41 Hosmer DW, Lemeshow S. Confidence interval estimation of interaction. Epidemiology 1992:3:452-6.

42 Sweden OSo. Breast-feeding and smoking habits among parents of infants born in 2011. 2013. [cited 201523 March] http://www.socialstyrelsen.se/publikationer2013/ 2013-9-18.

43 Josefsson $A$, Wiréhn $A B$, Lindberg $M$, et al. Continuation rates of oral hormonal contraceptives in a cohort of first-time users: a population-based registry study, Sweden 2005-2010. BMJ Open 2013;3:e003401

44 Orbach $\mathrm{H}$, Shoenfeld Y. Hyperprolactinemia and autoimmune diseases. Autoimmun Rev 2007:6:537-42. 


\section{Clinical and epidemiological research}

45 Costanza M, Binart N, Steinman L, et al. Prolactin: a versatile regulator of inflammation and autoimmune pathology. Autoimmun Rev 2015;14:223-30.

46 Szekeres-Bartho J, Barakonyi A, Par G, et al. Progesterone as an immunomodulatory molecule. Int Immunopharmacol 2001;1:1037-48.

47 Lankarani-Fard A, Kritz-Silverstein D, Barrett-Connor E, et al. Cumulative duration of breast-feeding influences cortisol levels in postmenopausal women. J Womens Health Gend Based Med 2001;10:681-7.
48 Orellana C, Saevarsdottir S, Klareskog L, et al. Postmenopausal hormone therapy and the risk of rheumatoid arthritis: results from the Swedish EIRA population-based casecontrol study. Eur J Epidemiol 2015;30:449-57.

49 Orellana C, Wedrén S, Källberg H, et al. EIRA Study Group. Parity and the risk of developing rheumatoid arthritis: results from the Swedish Epidemiological Investigation of Rheumatoid Arthritis study. Ann Rheum Dis 2014;73: 752-5. 